\title{
Empowering the Quality Assurance (QA) in Encounter National and International Accreditation
}

\author{
Hendra Lukito ${ }^{1, *}$ Harif Amali Rivai ${ }^{2}$ \\ ${ }^{I}$ Management Department, Faculty of Economic, Universitas Andalas, Padang, West Sumatra, Indonesia \\ ${ }^{2}$ Management Department, Faculty of Economic, Universitas Andalas, Padang, West Sumatra, Indonesia \\ *Corresponding author.Email: hendralukito@eb.unand.ac.id
}

\begin{abstract}
This study aims to determine the role, main tasks and functions of the Quality Assurance (QA) in the Master of Management study program, Faculty of Economics, Universitas Andalas. The approach used in this research is literature review and the source of the data in this study is secondary data collected through writing about the roles and main duties and functions of QA. The results of this study provide recommendations to interested parties or policy makers related to increasing the role of QA such as study program and faculty leaders regarding the detailed roles and main tasks and functions of QA. It is hoped that the research will make QA as a quality assurance unit that can assist study program managers in activities related to quality assurance such as: preparing for accreditation and re-accreditation, preparing a student database.
\end{abstract}

Keywords: Quality assurance, main tasks and functions, master of management

\section{INTRODUCTION}

The demand to improve the quality of the teaching and learning process in higher education is becoming increasingly important. This condition can be seen from the demands of higher education stakeholders where universities must be able to produce graduates who have high competence and are able to compete in the job market. The good quality of the teaching and learning process is very determined by the quality of the resources that are owned in implementing the quality of the teaching and learning process such as: students, lecturers and the facilities available in quality of the teaching and learning process activities (1).

Quality of the teaching and learning process can be identified through evaluations conducted by universities both internally and externally. The evaluation at Universitas Andalas is carried out with Internal Quality Audit activities for evaluation from the university of study programs (1) or majors and BAN-PT accreditation for external accreditation which must be done once a year for AMI and once five years for BAN-PT accreditation (4). Now and in the future, higher education institutions are also required to evaluate the quality of the teaching and learning process with assessments carried out by regional and international accreditation agencies. This condition is supported by the existence of a regulation from the Minister of Education and Culture which states that universities that have been assessed by an international accreditation agency recognized by the ministry no longer need to conduct an assessment by BAN-PT. This means that universities including Universitas Andalas are required to be able to improve the quality of the teaching and learning process in order to get a good assessment by international accreditation agencies.

The main problem faced by universities including Universitas Andalas in carrying out the teaching and learning process evaluations both by BAN-PT (5) and by international accreditation agencies is the preparation of accreditation forms that have not fully involved the Quality Assurance at the study program or department level. In the prevailing practice, QA has been formed at the study program or department 
level with a decree from the dean of each faculty at Universitas Andalas. But in each accreditation form preparation the most involved party is the study program or department with a team consisting of lecturers and educational staff in the study program/department.

This condition is compounded by the absence of good coordination in preparing accreditation forms both between the heads of study programs/departments, the drafting team and QA who should work together in preparing data and making reports for BAN-PT accreditation as well as for international accreditation (6). This coordination is needed so that the activity of compiling accreditation forms which goes through a long process can produce forms that describe the real situation of the study program/department. In accordance with its function, the QA is an institution that is closely related to these activities (2). But in practice QA itself has not been able to carry out its function to the fullest, including in the Master of Management study program, Faculty of Economics, Universitas Andalas.

The Master of Management Study Program of the Faculty of Economics, Universitas Andalas is one of the study programs under the Management Department which carries out lectures for the master or bachelor degree level. This study program is one of the study programs that are in great demand by students both because the available resources are very adequate coupled with the location of the campus which is located in a strategic location, namely in the city center. Currently Master of Management Study Program has carried out several accreditation activities both nationally and internationally. For the last few years, MM has received an A predicate for national accreditation by BAN-PT (7). Finally, MM has also received accreditation from an international accreditation agency, namely ABEST 21.

In preparing PBM assessments both internally and externally in Master of Management study program, the role of QA has not been optimal in accordance with the main tasks and functions that have been regulated both by LP3M Universitas Andalas (3) and in accordance with the Decree of the Dean of the Faculty of Economics, Universitas Andalas. QA should be maximally involved in the accreditation process in the Master of Management study program starting from data collection, compiling forms and documentation of both national and international accreditation activities. So far, in carrying out accreditation activities, it is always identical to the duties or jobs of the management of the study program or department where this condition will certainly not be optimal because the manager of the study program or department has also been busy with routine activities in managing the study program or department.

Based on the explanation above, it is necessary to conduct research to find out how to optimize the role of QA in the implementation of accreditation activities both nationally, regionally and internationally. Especially with the regulation of the Minister of Education and Culture that just came out regarding the sending and receiving of online accreditation forms through the Online Higher Education Accreditation System (SAPTO) application and the criteria in the accreditation form which were originally only 7 criteria now have become 9 criteria $(8,9,10)$. This development has also become a starting point for study programs or departments including Master of Management Study Program to maximize the role and function of QA (2).

The specific purpose of this research to be carried out is to determine the function and role of QA in helping study programs or departments, especially in Master of Management Study Program, so that in the future the existence of QA is truly in accordance with its assignments from faculties and universities. In addition, research also tries to provide input to decision makers in determining the main tasks and functions of QA in accreditation activities so that they can optimally help study programs or departments so that the accreditation results are also better.

The urgency of this research to be carried out is in an effort to increase the role and involvement of QA in assisting study programs or departments in preparing the completeness of accreditation both national and international in all stages of preparing accreditation forms. There are lots of QA involvement in the accreditation process starting from data collection, making the necessary forms including helping to prepare the documents needed during a visit to the study program or department.

\section{RESEARCH METHOD}

\subsection{Research Design}

In accordance with the research objectives to further improve the role and function QA in Master of Management Study Program, Faculty of Economics, Universitas Andalas, this research is a descriptive survey technique, namely: a study conducted to obtain data from the phenomenon that occurs and seek information factual, both about the social and economic institutions of a group or region (1). This study used qualitative approach through literature review. 


\subsection{Sources of Data}

The data used in this study can be divided into two, namely:

a. Primary data

Irawan (11) states that primary data is data taken directly without intermediaries from the source. Primary data is data that comes directly from the source data collected specifically and directly related to the research problem to be studied. The primary data sources in this study were obtained from interviews conducted with faculty leaders, study program leaders or departments, the BAPEM team of the Faculty of Economics, Universitas Andalas who became the information in this study.

b. Secondary Data

Secondary data is derived from documents (2) were obtained from various sources, both internal and external (12). Internal data is the data that comes from the organization where research is conducted external data are: data originating from outside the organization.

\subsection{Data Collection Techniques}

The steps taken in collecting data in this study are (13):

1. Formulate research problems and determine research objectives.

2. Determine the concept and review the literature.

3. Determine the informant.

4. Interview with informants after preparing a list of questions.

5. Data processing.

6. Analysis and reporting.

\section{RESULTS}

\subsection{Current Conditions Main Duties and Functions of $Q A$}

As explained in the previous section, this section will compare the current conditions of the role, main tasks and functions of the QA in the Master of Management study program that has been and is currently running with the expected conditions after a literature review on the role and the main tasks and functions of the QA.

Based on the quality document compiled by the Institute for Educational Development and Quality Assurance (LP3M), Universitas Andalas, in general the roles, main tasks and functions of $\mathrm{QA}$ at the study program level are as follows (1):

1. The process of evaluating the implementation of the SPMI standards is carried out by LP3M at the university level, BAPEM at the Faculty/Postgraduate level and QA at the study program level.

2. QA evaluates the implementation of the learning process at the department/study program/department level every semester.

3. QA evaluates the implementation of SPMI standards at the study program level.

4. The responsibilities and authorities of the department/ study program level quality assurance system are:

A. Monitoring and Evaluation profile of graduates.

B. Monitoring and Evaluation of graduate learning outcomes.

C. Monitoring and Evaluation of course learning outcomes.

D. Monitoring and Evaluation lecturers planning.

E. Monitoring and evaluation on the attendance level of lecturers and students.

F. Monitoring and Evaluation on the suitability of lecturers planning with learning.

G. Monitoring and Evaluation about the quality of the questions.

The explanation above has put QA in a very important position with regard to quality assurance at the department or study program level, but in practice this condition is very far from these roles and functions. Included in the Master of Management study program, Faculty of Economics, Universitas Andalas, which is a master study program that has been nationally accredited through BAN-PT accreditation and international accreditation, namely ABEST-21. Accreditation for a study program is proof that quality assurance has been carried out in accordance with standards, especially in the learning process carried out. This condition needs to be improved by optimizing the role and duties of QA to master of management study program so as to achieve a more optimal. 


\subsection{Alternative Increasing the Role and Task of $Q A$}

Literature review studies that have been carried out to obtain a suitable scheme to be applied to increase the role and main duties and functions of QA in the master management program are: (several sources about the role and main tasks and functions of QA)

1. Alternative1 (15):

Main tasks:

- Carry out the quality assurance process at the study program level and coordinate with the quality assurance team at the faculty and university level.

- To be fully involved in the internal and external quality assurance of the study program.

- Together with the head of the study program compile the program specifications, work instructions and supporting documents, compile self-evaluation documents and prepare for accreditation/re- accreditation

- Together with the study program leader coordinate quality assurance activities at the study program level.

b. Periodic Tasks:

- Coordinating for the preparation of quality audits.

- Monitoring the quality assurance process at the study program level.

- Coordinating with study program leaders regarding follow-up monitoring and evaluation results.

c. Responsible:

- Responsible for secretarial duties or governance of QCC.

- Responsible for improving academic quality and developing a quality assurance system.

- Responsible for quality assurance system documents.

- Responsible for the implementation of monitoring and evaluation.

2. Alternative 2 (16):

At the study program level, the organization that is responsible for coordinating the implementation of the academic quality assurance system is the Quality Control Group (QA). QA has the following main duties and functions:

a Together with the study program leader to coordinate academic quality assurance activities at the study program level;

b. Together with the study program leader to prepare Study Program Specifications and Work Instructions and supporting documents;

c. Together with the head of the study program to monitor the preparation of the SelfEvaluation and Self-Evaluation Based Study Program (EPSBED) documents:

d. Together with the head of the study program make preparations for accreditation or reaccreditation purposes;

e. Assisting study program leaders in activities and work programs in order to achieve quality standards.

Internal quality assurance mechanisms at the study program level are implemented by referring to the Plan- Do-Check/Evaluate-Action/Improve framework. At the planning stage (Plan), the mechanisms implemented by the study program are as follows:

a. Defining the vision, mission and objectives and translating them into the Strategic Plan and Operational Plan.

b. Compile and determine the Study Program Specifications.

c . Compile and develop a learning system based on the specifications of the study program.

d . Develop documents Work Instructions and other supporting documents for the implementation of academic activities. Documents compiled must refer to the Procedure Guidelines and Quality Guidelines at the faculty level.

e. Prepare Quality Plans, Quality Goals and conduct monitoring and analysis of the achievement of the Study Program Quality Goals every semester.

At the implementation stage (Do), the mechanism that runs with regard to academic quality assurance at the study program level is implementing work programs in accordance with the Annual Work Plan and Budget (RKAT) in addition to carrying out learning activities guided by the study program specifications. At the implementation stage, the Quality Control Group (QA) is required to perform internal monitoring and evaluation functions in the context of controlling the quality of work and learning programs. Therefore, the Quality Control Group (QA) is obliged to prepare a monitoring and evaluation report which must be known by the head of the study program to be submitted to the Quality Assurance Commission (QAC). The monitoring and evaluation report is then followed up in a meeting to discuss the results of monitoring and evaluation 
which is attended by faculty leaders (Deans and Deputy Deans), study program leaders (Head of Study Program and Secretary), Quality Assurance Commission (QAC), and Quality Control Group (QA). In the evaluation stage (Check/Evaluate), each element is required to carry out an internal monitoring and evaluation function in order to control the quality of the work program. At the stage of improvement actions (Action/Improve), Chairman of the Program prepare an action plan in response to the results of monitoring and evaluation. The results of monitoring and evaluation as well as the followup plan must be reported periodically/every semester to the Dean. In order to increase the achievement of compliance (Compliance degree) to the faculty Academic Standards, the study program is audited by the faculty (in coordination with PPM) based on the SPMI AMI Procedure Guidelines by an internal auditor appointed by the chancellor through an assignment letter.

3. Alternative 3 (17):

QA is a monitoring system carried out by the department, so that the improvement of the study program can be well organized.

The duties and functions of QA are as follows:

a Preparation of Study Program Specifications.

b. Preparation of Quality Manual (MP).

c. Preparation of Work Instructions (IK) and Standard Operating Procedures (SOP) in accordance with academic regulations, academic policies, procedure manuals, academic standards and faculty level academic quality manuals.

d Preparation of reports on the results of the evaluation of the learning process.

e. Reporting each indicator based on the quality of the study program for periodic evaluation.

4. Alternative 4 (18):

The quality assurance system of the study program is implemented by the Quality Control Group (QA). Quality assurance is a process of determining, fulfilling, evaluating, controlling, and developing quality consistently and continuously. The entire process must be well documented to serve as a reference for the implementation and evaluation of quality assurance. In running the quality assurance system, the Quality Control Group needs to have guidelines in carrying it out.

Work description on Quality Control Circle (QCC) is:

a Prepare quality documents (Quality Policy,
Quality Standards, and Quality Manuals) for Study Program.

b. Develop Standard Operating Procedures.

c. Develop lecture monitoring instruments and lecturer performance evaluations.

d. Compile a service satisfaction questionnaire to students.

e. Carry out lecture monitoring and lecturer performance evaluation.

f. Analyze the results of lecture monitoring and lecturer performance evaluation.

g Making lecture monitoring reports and evaluating lecturer performance.

h Report the results of the report to the head of the study program.

i Coordinate with QA Faculty to carry out monitoring and evaluation in the faculty.

j. In coordination with the Institute for Educational Development and Quality Assurance (LP3M) and the QA at Faculty level in implementing the monitoring held by the LP3M.

5. Alternative 5 (19):

At the departmental level, the person in charge of QA is the Head of the Department, the chairperson of QA is the Secretary of the Department and the members are formed according to the needs of the department. QA task is to assist the Head of the Department in:

(a) Monitoring the implementation of all academic and non-academic activities in accordance with the procedures, provisions, agreements and laws in force,

(b) Monitoring the implementation of all academic and non-academic activities in order to meet the quality standards and quality objectives that have been set,

(c) Conducting evaluations with the Head of the Department for earlier corrective action on the implementation of all academic and non-academic activities in the scope of work,

(d) Coordinating the preparation of selfevaluation reports according to predetermined standards and parameters.

6. Alternative 6 (20):

In carrying out its duties, it refers to the Implementation Guidelines from LP3M Universities and GJMF. The Quality Assurance 
Unit is tasked with:

a) Developing Internal Quality Assurance Standards for study programs in carrying out the duties and functions of implementing academic education in each Study Program.

b). Prepare Standard Operating Procedures (SOP).

c) Carry out monitoring and evaluation of the implementation of academic education at the study program level.

d). Coordinating with GJMF.

7. Alternative 7 (21):

Study Program Quality Control Clusters are study program instruments that carry out the quality assurance process at the study program level, particularly in monitoring reports that have been determined by the study program and submitting recommendations for continuous improvement of lecture implementation.

Main Duties and Functions of the Chair of the Study Program Quality Control Group:

a Compile quality documents, lecture monitoring instruments and lecturer performance evaluation, Standard Operating Procedures, and service satisfaction questionnaires to students.

b. Coordinating, monitoring, and evaluating the implementation of tasks carried out by members of the QA team.

c. Responsible for quality assurance activities carried out by QA.

Main Duties and Functions of the Secretary of the Quality Control Group study program:

a Assist the Chair in compiling quality documents, lecture monitoring instruments and lecturer performance evaluation, Standard Operating Procedures, and service satisfaction questionnaires to students.

b. Assisting the chairman in carrying out monitoring and evaluation of the implementation of tasks carried out by members of the QA team.

c. Responsible for implementing and archiving correspondence related to QA.

d. Responsible for planning, implementation and results of the agenda of routine meetings, coordination meetings and activity evaluation meetings.

e. Assist the chairman in preparing the completeness of the quality assurance activities carried out by QA.

f. Carry out quality assurance activities organized by QA.

Main Duties and Functions of Members of the Quality Control Group study program:

a. Assist the chairman in compiling quality documents, lecture monitoring instruments and lecturer performance evaluation, Standard Operating Procedures, and service satisfaction questionnaires to students.

b. Responsible for collecting the supporting documents needed in the quality assurance system.

c. Assisting with administrative work and documentation of daily activities and minutes of QA meetings.

d. Assisting the management of the QA database.

e. Carry out quality assurance activities organized by QA.

8. Alternative 8 (22):

Work unit QA is the quality assurance implementer at the work unit/study program level who is responsible to the head of the related work unit. Become part of and under the coordination of the SPM team. QA work unit is tasked with:

a Ensuring that SPMI has been executed properly and correctly follows the PPEPP pattern (planning, implementation, evaluation, control and improvement) in related work units in accordance with applicable standards and regulations.

b. Check and evaluate the implementation of SPMI in related work units by using applicable instruments.

c. Coordinating and monitoring the implementation of internal quality assurance programs in related units.

d. Identifying incidents that are not in accordance with the rules/procedures and standards applicable in the relevant work unit, which are at risk of achieving quality objectives and work targets, as well as reporting in writing to the head of the work unit periodically about these incidents and coordinated to the SPM secretariat.

e. Anticipating and providing written input to the relevant work unit leader regarding corrective actions for non-conformities that arise in accordance with the commitments that have been given. 
f Prepare a written report on the results of the implementation of internal quality assurance to be submitted to the leadership through SPM.

g Actively participate in continuous improvement initiatives and process control.

i. Carry out the assigned tasks by complying with and complying with quality standards and applicable laws.

\section{DISCUSSION}

Explanation above passages that describe about current condition of Duty and Function of QA then this section will be explained about the organizational structure and the duties that will be recommended for adoption at QA course master of management Faculty Economics, Universitas Andalas.

Various literature reviews described in the previous section illustrate that the position of QA is the same as the position of QA in the organizational structure that already exists at Universitas Andalas. Where the sequence of QA positions is under the Quality Assurance Agency (BAPEM) at the faculty level and the Institute for Educational Development and Quality Assurance (LP3M) at the university level. The literature that has been discussed in the previous section illustrates that QA coordinates with BAPEM and LP3M in carrying out their roles and duties related to quality assurance at the department or study program level.

The main duties and functions of QA in the explanation of the manual issued by LP3M Universitas Andalas have not yet explained in detail the job descriptions of the QA team or individually consisting of the chairman, secretary and members. Currently the composition of the existing QA team, including the Master of Management study program, Faculty of Economics, only consists of a chairman and members. Based on some of the alternatives that have been presented above, in this literature review recommendations are given to policy makers to make details of the main tasks and functions, both as a team and individually from QA.

Job descriptions that describe the main tasks and functions of the recommended QA to be implemented are:

1. Together with the study program leader to coordinate academic quality assurance activities at the study program level;

2. Together with the study program leader to prepare Study Program Specifications and Work Instructions and supporting documents;
3. Together with the head of the study program to monitor the preparation of the Self-Evaluation and Self-Evaluation Based Study Program (EPSBED) documents;

4. Together with the head of the study program make preparations for accreditation or reaccreditation purposes;

5. Assisting study program leaders in activities and work programs in order to achieve quality standards.

Meanwhile, the main tasks and functions of each member of the QA team are:

Main Tasks and Functionality head of Quality Control Circle (QCC) study program is:

a Compile quality documents, lecture monitoring instruments and lecturer performance evaluation, Standard Operating Procedures, and service satisfaction questionnaires to students.

b. Coordinating, monitoring, and evaluating the implementation of tasks carried out by members of the QA team.

c. Responsible for quality assurance activities carried out by QA.

Main Duties and Functions of the Secretary of the Quality Control Study Program are:

a Helping to preparing quality documents, instrument monitoring and performance evaluation of faculty lectures, Standard Operating Procedures, as well as services to student satisfaction questionnaires.

b. Assisting the chairman in carrying out monitoring and evaluation of the implementation of tasks carried out by members of the QA team.

c. Responsible for implementing and archiving correspondence related to QA.

d. Responsible for planning, implementing and the results of the agenda for routine meetings, coordination meetings and activity evaluation meetings.

e. Assist the chairman in preparing the completeness of the quality assurance activities carried out by QA.

f. Carry out quality assurance activities organized by QA.

Main Duties and Functions of Members of the Quality Control Group study program are:

a Assist the chairman in compiling quality documents, lecture monitoring instruments and lecturer performance evaluation, Standard Operating Procedures, and service satisfaction 
questionnaires to students.

b. Responsible for collecting supporting documents required in the quality assurance system as assigned by the head of the cluster.

c. Assisting with administrative work and documentation of daily activities and minutes of QA meetings.

d. Assisting the management of the QA database.

e. Carry out quality assurance activities organized by QA.

\section{CONCLUSION}

The conclusions that can be drawn from the previous explanation are:

1. The position of QA is very important as part of the quality assurance system in higher education where QA coordinates with quality assurance agencies at the faculty and university level.

2. The main tasks and job descriptions of QA must be detailed to make it easier to carry out the work in an effort to achieve the goals and objectives of the quality assurance agency.

3. In order for QA in the Economics Faculty management master program to be more optimal in working, it is necessary to formulate the main tasks of the functions of individual team members consisting of the chairman, secretary and members.

4. From the alternative roles and main duties and functions of QA that have been discussed and recommended, the important task of QA is to assist study programs in preparing accreditation and reaccreditation of study programs and to assist study programs to complete the required student data.

\section{ACKNOWLEDGMENTS}

This research was funded by: Institution for the Development of Education and Quality Assurance (LP3M), Universitas Andalas through research grant for education and quality assurance (PPMP) budget year 2020 .

\section{REFERENCES}

[1] Institution for the Development of Education and Quality Assurance (LP3M), Universitas Andalas (2017). Internal Quality Assurance System Guidelines Universitas Andalas 2018-2022 SPMI03-01-01

[2] Institution for the Development of Education and Quality Assurance (LP3M), Universitas Andalas (2017). Internal Quality Assurance System Manual Universitas Andalas 2018-2022 SPMI-03-02-01
[3] Institution for the Development of Education and Quality Assurance (LP3M), Universitas Andalas (2017). Internal Quality Assurance System Standard Universitas Andalas 2018-2022 SPMI03-03-01

[4] The National Accreditation for Higher Education, Ministry of Culture and Education. (2008).

Accreditation of Bachelor Study Programs

[5] The National Accreditation for Higher Education, Ministry of Culture and Education. (2008). Academic Text Accreditation of Bachelor Study Programs

[6] The National Accreditation for Higher Education, Ministry of Culture and Education. (2008). Standards and Procedures Accreditation of Bachelor Study Programs.

[7] The National Accreditation for Higher Education, Ministry of Culture and Education. (2008). Guide for Form Filling Accreditation of Bachelor Study Programs.

[8] The National Accreditation for Higher Education, Ministry of Culture and Education. (2008). Assessment Guidelines Accreditation of Bachelor Study Programs.

[9] The National Accreditation for Higher Education, Ministry of Culture and Education. (2008). Assessment Matrix Instruments Accreditation of Bachelor Study Programs.

[10] The National Accreditation for Higher Education, Ministry of Culture and Education. (2008). Guidelines for Field Assessment .

[11] Irawan, P. (2004). Logic and Research Procedures. Jakarta, STIALAN Press.

[12] Sekaran, U., \& Bougie, R. (2016). Research Methods for Business. United Kingdom: John Wiley\& Ons Ltd.

[13] Hair, J.F., et al. (2010). Multivariate Data Analysis. (7th edition). New Jersey: Pearson Education Inc.

[14] Quality Assurance Institution (2020). Procedure Guidelines for Quality Control for Study Programs Study, Universitas Islam Negeri (UIN) Walisongo: http://walisongo.ac.id

[15] Quality Assurance Unit (2020). Quality Assurance Standard, Universitas Sumatera Utara (USU): http://akuntansi.usu.ac.id.

[16] Quality Assurance Unit (2020). Internal Quality Assurance System, Universitas Sriwijaya (UNSRI): http://unsri.ac.id.

[17] Quality Assurance (2020). Quality Assurance Unit, PT Raharja: http://quality.Raharja.ac.id.

[18] Quality Assurance Unit (2020). Job description 
of the Quality Assurance Unit and Work Program of the Internal Assurance Unit, Politeknik Negeri Padang (PNP): http://www.pnp.ac.id.

[19] Quality Assurance Group (2020). Job Description for Quality Assurance Unit, Universitas Mulawarman (UNMUL): http: // unmul.ac.id

[20] Quality Assurance Office (2020). Quality Control Group, IPB University.

[21] Quality Assurance Unit (2020). Internal Assurance Unit, Universitas Jambi (UNJA).

[22] Quality Assurance Unit (2020). Internal Quality Assurance, Universitas Tanjung Pura (UNTAN): http://untan.ac.id. 